\title{
A Validation Study of Administrative Data Algorithms to Identify Patients with Parkinsonism with Prevalence and Incidence Trends
}

\author{
Debra A. Butt ${ }^{a, b}$ Karen Tu ${ }^{a, c, d} \quad$ Jacqueline Young ${ }^{c}$ Diane Green ${ }^{c}$ Myra Wang ${ }^{c}$ \\ Noah Ivers $^{\mathrm{a}, \mathrm{e}}$ Liisa Jaakkimainen ${ }^{\mathrm{a}, \mathrm{c}, \mathrm{f}}$ Robert Lam ${ }^{\mathrm{d}}$ Mark Guttman $^{\mathrm{g}}$ \\ ${ }^{a}$ Research Institute, Department of Family and Community Medicine, University of Toronto, Toronto, Ont., \\ ${ }^{b}$ Department of Family and Community Medicine, The Scarborough Hospital, Scarborough, Ont., ' Institute for Clinical \\ Evaluative Sciences (ICES), d Toronto Western Hospital Family Health Team, University Health Network, ${ }^{e}$ Department \\ of Family and Community Medicine, Women's College Hospital, ${ }^{f}$ Department of Family and Community Medicine, \\ Sunnybrook Health Sciences Centre, Toronto, Ont., ${ }^{9}$ Centre for Movement Disorders, Markham, Ont., Canada
}

\section{Key Words}

Parkinsonism - Administrative data - Validation - Sensitivity .

Predictive values · Prevalence · Incidence

\begin{abstract}
Background: Epidemiological studies for identifying patients with Parkinson's disease (PD) or Parkinsonism (PKM) have been limited by their nonrandom sampling techniques and mainly veteran populations. This reduces their use for health services planning. The purpose of this study was to validate algorithms for the case ascertainment of PKM from administrative databases using primary care patients as the reference standard. Methods: We conducted a retrospective chart abstraction using a random sample of 73,003 adults aged $\geq 20$ years from a primary care Electronic Medical Record Administrative data Linked Database (EMRALD) in Ontario, Canada. Physician diagnosis in the EMR was used as the reference standard and population-based administrative databases were used to identify patients with PKM from the derivation of algorithms. We calculated algorithm performance using sensitivity, specificity, and predictive values
\end{abstract}

and then determined the population-level prevalence and incidence trends with the most accurate algorithms. Results: We selected, ' 2 physician billing codes in 1 year' as the optimal administrative data algorithm in adults and seniors $(\geq 65$ years) due to its sensitivity (70.6-72.3\%), specificity (99.9$99.8 \%)$, positive predictive value (79.5-82.8\%), negative predictive value (99.9-99.7\%), and prevalence (0.28-1.20\%), respectively. Conclusions: Algorithms using administrative databases can reliably identify patients with PKM with a high degree of accuracy.

(C) 2014 S. Karger AG, Basel

\section{Introduction}

Parkinson's disease (PD) is a chronic, progressive neurodegenerative disorder without known etiology [1] and a leading cause of neurological disability in the adult population [2]. The diagnosis of PD is based on clinical criteria characterized by rest tremor, bradykinesia, rigidity and postural instability $[3,4]$. Patients with PD and other forms of secondary Parkinsonism (collectively referred to

\section{KARGER}

E-Mail karger@karger.com

www.karger.com/ned (c) 2014 S. Karger AG, Basel

0251-5350/14/0431-0028\$39.50/0
Dr. Debra A. Butt

Ellesmere Health Care Centre

2060 Ellesmere Road, Units 1-5

Scarborough, ON, M1H 2V6 (Canada)

E-Mail debra.butt@utoronto.ca 
as $\mathrm{PKM}$ ) have greater than double the mortality rates of age and sex-matched controls [1]. PKM is associated with an average annual cost of physician services 1.4 times greater than controls [1]. Worldwide estimates of PD alone are projected to double from 4.1-4.6 million in 2005 to $8.7-9.3$ million by 2030 [5].

Population-based administrative databases can maintain a PKM surveillance system, allow for longitudinal studies using data linkage techniques and provide PKM cases and non-cases that can be compared on comorbid conditions [6]. Although administrative data are a convenient and an important source for studying specific patient populations, the challenge is to create a valid approach for correctly identifying patients with PKM. Determining the accuracy of diagnostic codes or combinations of codes (case ascertainment algorithms) for PKM through a validation study is critical in order to avoid misclassification error, which represents an important form of research bias using health administrative databases [7].

Four previous studies validated algorithms for $\mathrm{PD} /$ PKM using administrative databases [8-11] but each used nonrandom sampling methods to select PD/PKM cases and non-cases for validation [8-11]. Furthermore, one study involved only seniors [10] and the other three were limited to veterans $[8,9,11]$. In this study, we performed a healthcare administrative data validation for identifying patients with PKM using a primary care electronic medical record (EMR), a more general population, as the reference standard.

\section{Methods}

We conducted a retrospective EMR chart abstraction study using a random sample of all eligible patients aged $\geq 20$ from primary care practices to identify those patients with and without PKM. These patients were then linked in an encrypted, anonymous manner to healthcare administrative databases in the province of Ontario, Canada housed at the Institute for Clinical Evaluative Sciences (ICES), Toronto. Multiple administrative data algorithms using combinations of physician billing claims, hospitalization diagnoses and/or pharmacy prescription data were tested and validated for PKM within the administrative data. We used the modified Standards for Reporting of Diagnostic Accuracy (STARD) criteria to report our findings [7] and our methodology follows recent recommendations on the reporting and study design of administrative data validation studies $[6,12,13]$.

\section{Reference Standard}

The Electronic Medical Record Administrative data Linked Database (EMRALD) held at ICES was used as the validation reference standard. EMRALD consists of data from family physicians in Ontario using the EMR software Practice Solutions ${ }^{\circledR}$. All the clinically relevant information contained in the family physician patient chart is collected into EMRALD. This includes all physician office encounters, the cumulative patient profile (CPP) containing current and past medical history, family history, risk factors, allergies, immunizations, all laboratory and diagnostic test results, prescriptions recorded by the family physician, specialist consultation letters, and hospital discharge summaries. The data used in this validation study were extracted from EMRALD between June and November 2011. We identified a study cohort of adult patients as of December 31, 2010 who met the following inclusion criteria: had a valid health card number and date of birth, were registered to one of the 84 participating EMRALD family physicians, and had at least one visit in the one year prior to the extraction date. There were 73,003 EMR patients who met the criteria.

Two standardized data abstraction tools for PKM and PD were created with input from family physicians and neurologists specialized in PD to classify the diagnosis of each EMR patient to be abstracted (online suppl. fig. 1; for all online suppl. material, see www.karger.com/doi/10.1159/000365590). We used an automated electronic text-matching search strategy on the 73,003 eligible EMR patients in order to identify all patients with a potential diagnosis of PKM (fig. 1). This pool of patients was reviewed by six trained chart abstractors (4 nurses and 2 physicians with experience in medical record abstraction) using the criteria provided by the abstraction tools. The abstractors were instructed to classify the patient as 'definitely' having PD or secondary PKM, 'possibly' having one of the conditions, not having PKM as the condition was ruled out ('not' PKM), or there was 'no mention' of the condition in the EMR. Each abstractor re-abstracted $5 \%$ of their charts to assess for intra-rater reliability and $5 \%$ of all the charts were double abstracted by two different abstractors to assess for inter-rater reliability. All trained abstractors were blinded to the administrative data diagnostic codes for all EMR patients.

The abstractors also recorded whether there was documentation of a neurologist diagnosis, symptom onset date and diagnosis date for $\mathrm{PD} / \mathrm{PKM}$ in the patient EMR, and if any of the 4 drug classes commonly used in the treatment of PD (levodopa drugs, MAO-B inhibitors, dopamine agonists and COMT inhibitors) were documented for each abstracted patient (online suppl. fig. 1). We also performed an automated text-matching drug search in the EMR where MAO-B inhibitors and COMT inhibitors were scored as 'definite' for PD/PKM, while levodopa drugs and dopamine agonists were scored as 'possible' for PKM.

When there was conflicting information in the patient EMR or more recent evidence about the diagnosis, the chart abstractors gave greater weight to diagnoses from neurologists and/or more recently detailed documented patient notes, thereby adhering to a temporal pattern of disease progression more indicative of this chronic disease. All EMR records were revalidated by expert review (DB) and any discrepancies or areas of misclassification were addressed. In order to determine the final classification of PD/ PKM, an overall global score was used based on EMR chart abstraction and the automated scoring of the drugs. Once patients were classified as having or not having PKM according to our overall global scores, we proceeded to administrative data algorithm generation and testing.

\section{Administrative Data Sources}

Population-based hospital, physician and pharmacy administrative data were from Ontario, the largest populated province of Canada with about 14 million residents and a universal healthcare 


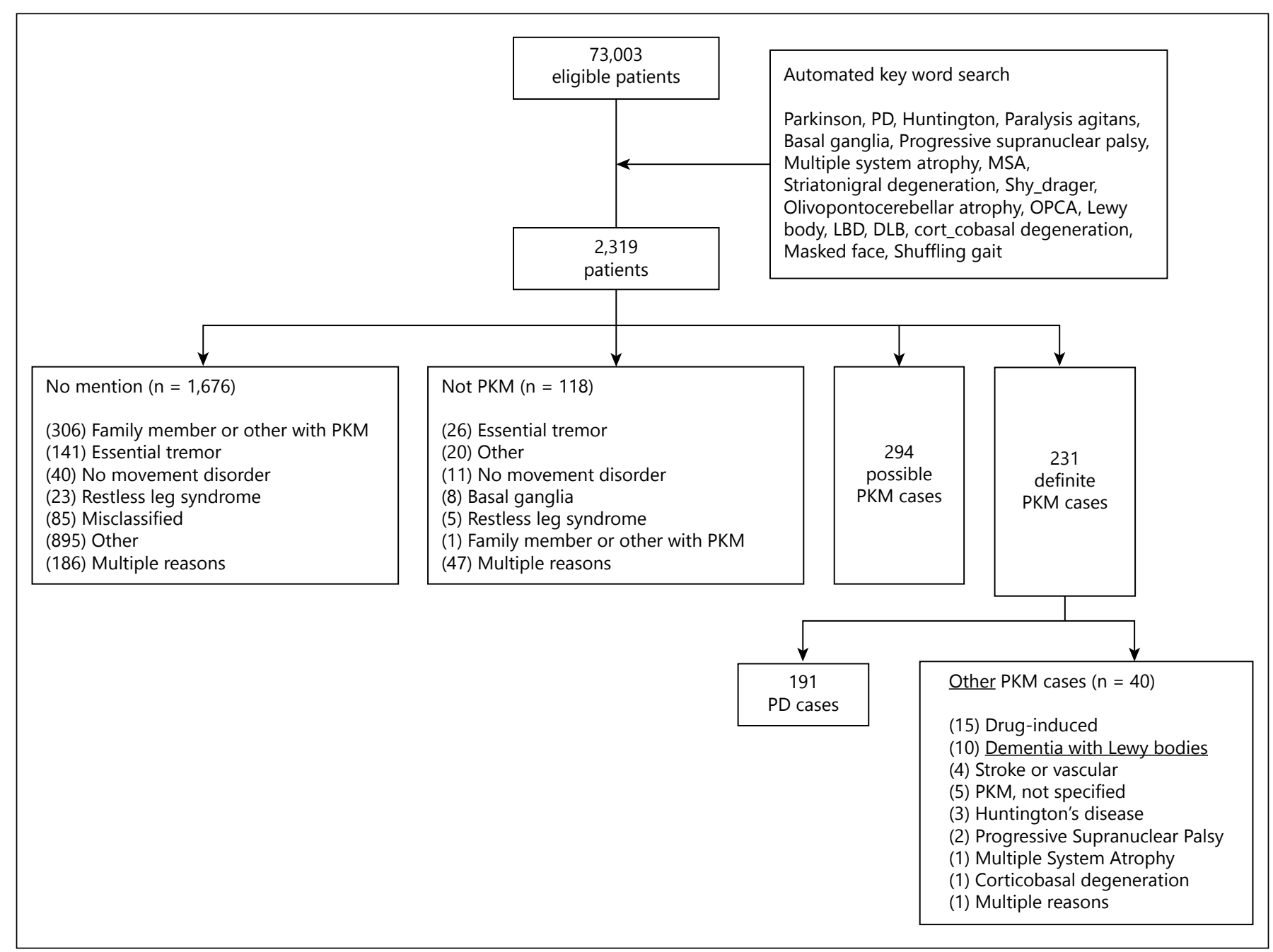

Fig. 1. $\mathrm{PD}=$ Parkinson's disease; $\mathrm{PKM}=$ Parkinsonism; $\mathrm{MSA}=$ multiple system atrophy; Shy_drager and cort_cobasal degeneration $=$ '_' means different variations of terms; OPCA = olivopontocerebellar atrophy; LBD and DLB = Dementia with Lewy bodies;

system. The following administrative databases were used: the Canadian Institute for Health Information hospital Discharge Abstracts Database (CIHI-DAD, providing detailed diagnostic information regarding hospital admissions [14] from 1998), the Ontario Health Insurance Plan (OHIP) physician claims database (containing physician billing information and diagnoses from 1991), the National Ambulatory Care Reporting System (NACRS) database, which captures all hospital-based and community-based ambulatory care including emergency departments from 2000, the Same Day Surgery Database (SDS, corresponding to same-day surgery or procedure stay from 1991) and the Ontario Drug Benefit Program (ODBP) prescription drugs database, which records all drugs prescribed from a minimally restrictive formulary for individuals aged $\geq 65$ years [15]. In Ontario, CIHI-DAD data used International Classification of Diseases (ICD)-9 codes with four digits until 2002 and thereafter switched to ICD-10 codes. ICD-9
Misclassified $=$ examples were personality disorder or peritoneal dialysis for PD; Other = diagnoses not related to PKM; Multiple reasons = more than 1 reason provided, which included any of the above-listed reasons except 'other'. 
We also tested algorithms with and without a 30-day skip period when using physician billing codes, recognizing that a cluster of codes within a 30-day period may simply indicate follow-up related to the initial presentation of PKM. In order to avoid this clustering effect, we elected to examine physician billing codes spread out over a 30-day period (30-day skip) as this may impact algorithm performance. The algorithms were applied to all administrative data until March 31, 2011.

\section{Statistical Analyses}

Sensitivity, specificity, positive predictive value (PPV), and negative predictive value (NPV) with their $95 \%$ confidence intervals (CI), and Youden's index and kappa were calculated for each algorithm. Sensitivity was the proportion of patients with an EMRdocumented PKM diagnosis who were identified as having the disease by administrative data. Specificity was the proportion of patients with PKM without EMR-documented disease who were identified as not having PKM by administrative data. PPV was the probability of those identified as having PKM who truly had this condition, while NPV was the probability of those identified as not having PKM, who truly did not have this condition. A discriminating test would have sensitivity, specificity, PPV and NPV close to $100 \%$, and Youden's index and kappa close to 1.0. We selected the optimal algorithms according to high PPV while also maximizing sensitivity and specificity in order to create a more homogeneous sample and avoid detecting false PKM cases [13]. EMR disease prevalence was calculated as the number of patients with PKM divided by the total number of eligible patients.

We applied the optimal algorithms to the entire population of Ontario and observed the prevalence and incidence trends from 2000 to 2010 for those aged $\geq 20$ and for those aged $\geq 65$. We used a 5-year run-in period from 1995 to 2000 where annual agestandardized prevalence and incidence reporting started in year 2000 to permit enough time for PKM cases to accumulate and to avoid errors in including prevalent PKM cases as incident cases during the earlier years of reporting. Annual rates were agestandardized to the 1991 Statistics Canada age distribution and to persons alive and registered with health care coverage in a given year in Ontario. The annual prevalence was determined by including PKM cases that were prevalent in the prior year, adding new incident cases in the same year and removing patients that had died or moved out of province. PKM patients were considered incident in the year they met all criteria of the algorithm.

All analyses were done using the binomial approximation method using SAS version 9.2 (SAS Institute, Cary, North Carolina, USA). This study received approval from Sunnybrook Research Ethics Board.

\section{Results}

We identified 2,319 potential patients after applying the automated key word search to the 73,003 eligible EMR charts (fig. 1). Of the 2,319 patients, we found that there was 'no mention' of a diagnosis of PKM in 1,676 EMR charts. In 306 of these 'no mention' charts, there was documentation of a family history or other person having
PKM and 85 patient EMR charts were misclassified such that the abbreviation 'PD' actually represented personality disorder or peritoneal dialysis as examples rather than Parkinson's disease. There were 40 EMR charts where there was documentation of no movement disorder. The majority of 'no mention' patient EMR records were other diagnoses not related to PKM $(n=895)$ and there were 186 EMR charts where more than 1 reason was provided (multiple reasons), which included anyone of the aforementioned reasons except 'other' (either family history or other person with PKM, essential tremor, no movement disorder, restless leg syndrome or misclassified). There were 118 EMR charts that were ruled out as not having PKM (not PKM) with reasons similar to the 'no mention' category (fig. 1).

There were 294 EMR charts defined as possible PKM cases and 231 definite PKM cases where 191 were classified as PD and 40 classified as other PKM (fig. 1). The majority of other PKM cases were drug-induced and 5 EMR charts documented PKM where 'not specified' indicated 'no mention' of etiology (fig. 1). Kappa scores for inter- and intra-rater reliability exceeded 0.80 indicating good agreement for all six chart abstractors. Expert review of the 2,319 EMR charts led to corrections of 13 patients classified as 'definite' for PKM: 7 became 'possible', 4 became 'no mention', and 2 became 'not' PKM and 7 patients were added as 'definite' PKM (3 from 'no mention' and 4 from 'possible'). The EMR characteristics of the study patients with PD/PKM are presented in table 1 . Most PKM patients were $\geq 65$ years $(82.7 \%)$, male $(60.2 \%)$, and had their diagnosis confirmed by a neurologist (66.7\%). The majority had PD (82.7\%) and of these patients, $86.4 \%$ were taking at least one anti-PD medication.

We then determined a working list of 22 algorithms for each age group in order to demonstrate our selection of the optimal algorithms (all algorithms available upon request). All algorithms in table 2 had excellent specificity (99.3-100.0\%), while sensitivities varied markedly for nondrug algorithms (26.0-82.7\%) and less so for algorithms involving drugs (61.0-87.0\%). Using ' 1 hospitalization diagnosis code ever' had the lowest sensitivity (26.0\%) of all the algorithms in those aged $\geq 20$ and upon review was prone to misclassification from mental health diagnoses with drug overdose. Having a specialist involved in the care of the PKM patient, ' 1 physician billing code by a specialist', in comparison to the algorithm of '1 physician billing code ever' decreased the sensitivity from 82.7 to $69.3 \%$ with an increase in PPV from 43.9 to $56.1 \%$. Increasing the number of physician billing codes over a 1 -year period generally decreased the sensitivity while in- 
Table 1. Characteristics of study patients with Parkinsonism (PKM)

\begin{tabular}{lccc}
\hline Characteristics & $\begin{array}{l}\text { Parkinsonism } \\
(\mathrm{n}=231)\end{array}$ & $\begin{array}{l}\text { Parkinson's disease } \\
(\mathrm{n}=191)\end{array}$ & $\begin{array}{l}\text { Other PKM } \\
(\mathrm{n}=40)\end{array}$ \\
\hline$\geq 65$ years, $\mathrm{n}(\%)$ & $191(82.7)$ & $162(84.8)$ & $71.7 \pm 12.1$ \\
Age* years, mean \pm SD & $74.0 \pm 10.2$ & $74.5 \pm 9.6$ & $18(45.0)$ \\
Male, $\mathrm{n}(\%)$ & $139(60.2)$ & $121(63.4)$ & $19(47.5)$ \\
Neurologist, $\mathrm{n}(\%)$ & $154(66.7)$ & $135(70.7)$ & $15(37.5)$ \\
$\geq 1$ Anti-PD drug, $\mathrm{n}(\%)$ & $180(77.9)$ & $165(86.4)$ & $18(45.0)$ \\
Symptom onset date, $\mathrm{n}(\%)$ & $115(49.8)$ & $119(62.3)$ & $18(45.0)$ \\
Diagnosis date, $\mathrm{n}(\%)$ & $137(59.3)$ & & \\
\hline
\end{tabular}

* Age December 31, 2010; PKM = Parkinsonism; PD = Parkinson's disease; $\mathrm{n}=$ number; \% = percentage; $\mathrm{SD}=$ standard deviation; Neurologist $=$ diagnosis documented by neurologist in EMR chart; PD drugs = levodopa drugs, MAO-B inhibitors, dopamine agonists and COMT inhibitors.

Table 2. Administrative Data Algorithms using the EMR as the Reference Standard to identify PKM patients $\geq 20$

\begin{tabular}{|c|c|c|c|c|c|c|c|c|c|c|c|}
\hline Algorithms & $\mathrm{TP}$ & $\mathrm{TN}$ & FN & FP & $\begin{array}{l}\text { Sensitivity } \\
(95 \% \mathrm{CI})\end{array}$ & $\begin{array}{l}\text { Specificity } \\
(95 \% \mathrm{CI})\end{array}$ & $\begin{array}{l}\text { PPV } \\
(95 \% \text { CI })\end{array}$ & $\begin{array}{l}\text { NPV } \\
(95 \% \text { CI })\end{array}$ & Kappa & $\begin{array}{l}\text { Youden } \\
\text { Index }\end{array}$ & $\begin{array}{l}\text { Prev. } \\
(\%)\end{array}$ \\
\hline \multicolumn{12}{|l|}{ No drugs } \\
\hline $1 \mathrm{H}$ or ER ever & 76 & 72,746 & 155 & 26 & $32.9(26.8-39.0)$ & $100.0(100.0-100.0)$ & $74.5(66.1-83.0)$ & $99.8(99.8-99.8)$ & 0.46 & 0.33 & 0.14 \\
\hline $1 \mathrm{P}$ ever & 191 & 72,528 & 40 & 244 & $82.7(77.8-87.6)$ & $99.7(99.6-99.7)$ & $43.9(39.2-48.6)$ & $99.9(99.9-100.0)$ & 0.57 & 0.82 & 0.60 \\
\hline $1 \mathrm{P}$ by a specialist & 160 & 72,647 & 71 & 125 & $69.3(63.3-75.2)$ & $99.8(99.8-99.9)$ & $56.1(50.4-61.9)$ & $99.9(99.9-99.9)$ & 0.62 & 0.69 & 0.39 \\
\hline $2 \mathrm{P}$ in 1 y by a specialist & 135 & 72,745 & 96 & 27 & $58.4(52.1-64.8)$ & $100.0(99.9-100.0)$ & $83.3(77.6-89.1)$ & $99.9(99.8-99.9)$ & 0.69 & 0.58 & 0.22 \\
\hline $2 \mathrm{P}$ in $2 \mathrm{y}$ & 166 & 72,723 & 65 & 49 & $71.9(66.1-77.7)$ & $99.9(99.9-100.0)$ & $77.2(71.6-82.8)$ & $99.9(99.9-99.9)$ & 0.74 & 0.72 & 0.29 \\
\hline $2 \mathrm{P}$ in $3 \mathrm{y}$ & 167 & 72,719 & 64 & 53 & $72.3(66.5-78.1)$ & $99.9(99.9-99.9)$ & $75.9(70.3-81.6)$ & $99.9(99.9-99.9)$ & 0.74 & 0.72 & 0.30 \\
\hline $3 \mathrm{P}$ in $1 \mathrm{y}$ & 136 & 72,754 & 95 & 18 & $58.9(52.5-65.2)$ & $100.0(100.0-100.0)$ & $88.3(83.2-93.4)$ & $99.9(99.8-99.9)$ & 0.71 & 0.59 & 0.21 \\
\hline $1 \mathrm{H}$ ever or $2 \mathrm{P}$ in $1 \mathrm{y}$ & 166 & 72,713 & 65 & 59 & $71.9(66.1-77.7)$ & $99.9(99.9-99.9)$ & $73.8(68.0-79.5)$ & $99.9(99.9-99.9)$ & 0.72 & 0.72 & 0.31 \\
\hline $1 \mathrm{Rx}$ and $(1 \mathrm{P}) \pm 6$ months & 152 & 72,748 & 79 & 24 & $65.8(59.7-71.9)$ & $100.0(100.0-100.0)$ & $86.4(81.3-91.4)$ & $99.9(99.9-99.9)$ & 0.75 & 0.66 & 0.24 \\
\hline$(1 \mathrm{Rx}$ and $1 \mathrm{P})$ in $1 \mathrm{y}$ & 152 & 72,748 & 79 & 24 & $65.8(59.7-71.9)$ & $100.0(100.0-100.0)$ & $86.4(81.3-91.4)$ & $99.9(99.9-99.9)$ & 0.75 & 0.66 & 0.24 \\
\hline $2 \mathrm{P}$ ever and $1 \mathrm{Rx}$ ever & 141 & 72,755 & 90 & 17 & $61.0(54.8-67.3)$ & $100.0(100.0-100.0)$ & $89.2(84.4-94.1)$ & $99.9(99.8-99.9)$ & 0.72 & 0.61 & 0.22 \\
\hline ( $2 \mathrm{P}$ in $1 \mathrm{y})$ or $(1 \mathrm{Rx}$ and $1 \mathrm{P})$ & 181 & 72,713 & 50 & 59 & $78.4(73.0-83.7)$ & $99.9(99.9-99.9)$ & $75.4(70.0-80.9)$ & $99.9(99.9-99.9)$ & 0.77 & 0.78 & 0.33 \\
\hline $\begin{array}{l}(2 \mathrm{P} \text { in } 1 \mathrm{y}) \text { or }(1 \mathrm{Rx} \text { and } \\
(1 \mathrm{P}) \pm 6 \text { months }) \\
1 \mathrm{Rx} \text { and }(1 \mathrm{H} \text { or } 1 \mathrm{P})\end{array}$ & 180 & 72,718 & 51 & 54 & $77.8(72.6-83.3)$ & $.9(99.9-99.9)$ & $76.9(71.5-82.3)$ & $.9(99.9-99.9)$ & 0.77 & 0.78 & 0.32 \\
\hline $\begin{array}{l} \pm 6 \text { months } \\
(1 \mathrm{H} \text { ever or }(2 \mathrm{P} \text { in } 1 \mathrm{y})) \text { or }\end{array}$ & 153 & 72,748 & 79 & 24 & $66.2(60.1-72.3)$ & $100.0(100.0-100.0)$ & $86.4(81.4-91.5)$ & $99.9(99.9-99.9)$ & 0.75 & 0.66 & 0.24 \\
\hline $\begin{array}{c}(1 \mathrm{Rx} \text { and }(1 \mathrm{H} \text { or } 1 \mathrm{P})) \\
(1 \mathrm{H} \text { ever or }(2 \mathrm{P} \text { in } 1 \mathrm{y})) \text { or } \\
(1 \mathrm{Rx} \text { and }(1 \mathrm{H} \text { or } 1 \mathrm{P})\end{array}$ & 181 & 72,697 & 50 & 75 & $78.4(73.9-83.7)$ & $99.9(99.9-99.9)$ & $70.7(65.1-76.3)$ & $99.9(99.9-99.9)$ & 0.74 & 0.78 & 0.35 \\
\hline
\end{tabular}

* Drugs only available to those $\geq 65$ years. $\mathrm{N}=73,003$ (231 PKM cases, EMR prevalence $=0.32 \%$ ). Algorithms reflect a 30-day skip with respect to physician billing codes except where indicated.

$\mathrm{TP}=$ True positive; $\mathrm{TN}=$ true negative; $\mathrm{FN}=$ false negative; $\mathrm{FP}=$ false positive; $\mathrm{PPV}=$ positive predictive value; $\mathrm{NPV}=$ negative predictive value; $\mathrm{CI}=$ confidence interval; Prev. = prevalence; $\mathrm{y}=$ year; $\mathrm{H}=$ hospitalization diagnosis code; $\mathrm{ER}=$ emergency visit code or same day surgery code; $\mathrm{P}=$ physician billing code; Specialist $=$ non-family physician; $\mathrm{Rx}=$ prescription including levodopa drugs, $\mathrm{MAO}-\mathrm{B}$ inhibitors, dopamine agonists and COMT inhibitors . 
Table 3. Administrative Data Algorithms using the EMR as the Reference Standard to identify PKM patients $\geq 65$

\begin{tabular}{|c|c|c|c|c|c|c|c|c|c|c|c|}
\hline Algorithms & $\mathrm{TP}$ & $\mathrm{TN}$ & FN & $\mathrm{FP}$ & $\begin{array}{l}\text { Sensitivity } \\
(95 \% \mathrm{CI})\end{array}$ & $\begin{array}{l}\text { Specificity } \\
(95 \% \mathrm{CI})\end{array}$ & $\begin{array}{l}\text { PPV } \\
(95 \% \text { CI })\end{array}$ & $\begin{array}{l}\text { NPV } \\
(95 \% \text { CI })\end{array}$ & Kappa & $\begin{array}{l}\text { Youden } \\
\text { Index }\end{array}$ & $\begin{array}{l}\text { Prev. } \\
(\%)\end{array}$ \\
\hline \multicolumn{12}{|l|}{ No drugs } \\
\hline $1 \mathrm{H}$ or ER ever & 67 & 14,155 & 124 & 13 & $35.1(28.3-41.8)$ & $99.9(99.9-100.0)$ & $83.8(75.7-91.8)$ & $99.1(99.0-99.3)$ & 0.49 & 0.35 & 0.56 \\
\hline $1 \mathrm{P}$ ever & 162 & 14,033 & 29 & 135 & $84.8(79.7-89.9)$ & $99.0(98.9-99.2)$ & $54.5(48.9-60.2)$ & $99.8(99.7-99.9)$ & 0.66 & 0.84 & 2.10 \\
\hline $1 \mathrm{P}$ code by a specialist & 135 & 14,106 & 56 & 62 & $70.7(64.2-77.1)$ & $99.6(99.5-99.7)$ & $68.5(62.0-75.0)$ & $99.6(99.5-99.7)$ & 0.69 & 0.70 & 1.40 \\
\hline $2 \mathrm{P}$ in $1 \mathrm{y}$ by a specialist & 116 & 14,150 & 75 & 18 & $60.7(53.8-67.7)$ & $99.9(99.8-99.9)$ & $86.6(80.8-92.3)$ & $99.5(99.4-99.6)$ & 0.71 & 0.61 & 0.93 \\
\hline $2 \mathrm{P}$ in $2 \mathrm{y}$ & 143 & 14,134 & 48 & 34 & $74.9(68.7-81.0)$ & $99.8(99.7-99.8)$ & $80.8(75.0-86.6)$ & $99.7(99.6-99.8)$ & 0.77 & 0.75 & 1.20 \\
\hline $2 \mathrm{P}$ in $3 \mathrm{y}$ & 144 & 14,132 & 47 & 36 & $75.4(69.3-81.5)$ & $99.7(99.7-99.8)$ & $80.0(74.2-85.8)$ & $99.7(99.6-99.8)$ & 0.77 & 0.75 & 1.30 \\
\hline $3 \mathrm{P}$ in $1 \mathrm{y}$ & 116 & 14,157 & 75 & 11 & $60.7(53.8-67.7)$ & $99.9(99.9-100.0)$ & $91.3(86.4-96.2)$ & $99.5(99.4-99.6)$ & 0.73 & 0.61 & 0.88 \\
\hline $1 \mathrm{H}$ ever or $2 \mathrm{P}$ in $1 \mathrm{y}$ & 143 & 14,133 & 48 & 35 & $74.9(68.7-81.0)$ & $99.8(99.7-99.8)$ & $80.3(74.5-86.2)$ & $99.7(99.6-99.8)$ & 0.77 & 0.75 & 1.20 \\
\hline \multicolumn{12}{|l|}{ With drugs* } \\
\hline $1 \mathrm{Rx}$ and $(1 \mathrm{P}) \pm 6$ months & 145 & 14,147 & 46 & 21 & $75.9(69.9-82.0)$ & $99.9(99.8-99.9)$ & $87.3(82.3-92.4)$ & $99.7(99.6-99.8)$ & 0.81 & 0.76 & 1.20 \\
\hline$(1 \mathrm{Rx}$ and $1 \mathrm{P})$ in $1 \mathrm{y}$ & 145 & 14,147 & 46 & 21 & $75.9(69.9-82.0)$ & $99.9(99.8-99.9)$ & $87.3(82.3-92.4)$ & $99.7(99.6-99.8)$ & 0.81 & 0.76 & 1.20 \\
\hline $2 \mathrm{P}$ ever and $1 \mathrm{Rx}$ ever & 135 & 14,153 & 56 & 15 & $70.7(64.2-77.1)$ & $99.9(99.8-99.9)$ & $90.0(85.2-94.8)$ & $99.6(99.5-99.7)$ & 0.79 & 0.71 & 1.00 \\
\hline$(2 \mathrm{P}$ in $1 \mathrm{y})$ or $(1 \mathrm{Rx}$ and $1 \mathrm{P})$ & 157 & 14,124 & 34 & 44 & $82.2(76.8-87.6)$ & $99.7(99.6-99.8)$ & $78.1(72.4-83.8)$ & $99.8(99.7-99.8)$ & 0.80 & 0.82 & 1.40 \\
\hline $\begin{array}{l}\text { (2 } \mathrm{P} \text { in } 1 \mathrm{y}) \text { or }(1 \mathrm{Rx} \text { and }(1 \mathrm{P}) \\
\pm 6 \text { months }) \\
1 \mathrm{Rx} \text { and }(1 \mathrm{H} \text { or } 1 \mathrm{P})\end{array}$ & 156 & 14,129 & 35 & 39 & $81.7(76.2-87.2)$ & $99.7(99.6-99.8)$ & $80.0(74.4-85.6)$ & $99.7(99.7-99.8)$ & 0.81 & 0.81 & 1.40 \\
\hline $\begin{array}{l} \pm 6 \text { months } \\
(1 \mathrm{H} \text { or }(2 \mathrm{P} \text { in } 1 \mathrm{y})) \text { or }\end{array}$ & 146 & 14,147 & 45 & 21 & $76.4(70.4-82.5)$ & $99.9(99.8-99.9)$ & $87.4(82.4-92.5)$ & $99.7(99.6-99.8)$ & 0.81 & 0.76 & 1.20 \\
\hline $\begin{array}{l}(1 \mathrm{Rx} \text { and }(1 \mathrm{H} \text { or } 1 \mathrm{P})) \\
(1 \mathrm{H} \text { or }(2 \mathrm{P} \text { in } 1 \mathrm{y})) \text { or }(1 \mathrm{Rx} \\
\text { and }(1 \mathrm{H} \text { or } 1 \mathrm{P})\end{array}$ & 157 & 14,119 & 34 & 49 & $82.2(76.8-87.6)$ & $99.7(99.6-99.8)$ & $76.2(70.4-82.0)$ & $99.8(99.7-99.8)$ & 0.79 & 0.82 & 1.40 \\
\hline
\end{tabular}

* Drugs only available to those $\geq 65$ years. $\mathrm{N}=14,359$ (191 PKM cases, EMR prevalence $=1.3 \%$ ). Algorithms reflect a 30-day skip with respect to physician billing codes except where indicated. $\mathrm{TP}=$ True positive; $\mathrm{TN}=$ true negative; $\mathrm{FN}=$ false negative; $\mathrm{FP}=$ false positive; $\mathrm{PPV}=$ positive predictive value; $\mathrm{NPV}=$ negative predictive value; $\mathrm{CI}=$ confidence interval; Prev. = prevalence; $\mathrm{y}=$ year; $\mathrm{H}=$ hospitalization diagnosis code; $\mathrm{ER}=\mathrm{emergency} \mathrm{visit}$ code or same day surgery code; $\mathrm{P}=$ physician billing code; Specialist = non-family physician; $\mathrm{Rx}=$ prescription including levodopa drugs, $\mathrm{MAO}$ - $\mathrm{B}$ inhibitors, dopamine agonists and COMT inhibitors.

creasing the PPV. Also, increasing the number of years with 2 physician billing codes decreased the PPV slightly with only a marginal increase in sensitivity. Based on these findings, we selected the optimal nondrug algorithm as ' 2 physician billing codes in 1 year' with a 30 -day interval between physician billing codes to identify PKM in those aged $\geq$ years due to its maximal validity indices: sensitivity (70.6\%), specificity (99.9\%), PPV (79.5\%), and NPV (99.9\%) (table 2). The absence of a 30-day interval between billing codes (no skip) for the optimal algorithm demonstrated a lower PPV (72.8\%), supporting the use of a 30-day interval between physician billing claims for PKM. The prevalence of PKM in the primary care EMRs was $0.32 \%$ compared to $0.28 \%$ using our optimal algo-

Validating Data Algorithms for

Parkinsonism rithm (table 2). The drug algorithm, '(2 physician billing codes in 1 year $)$ or $(1 \mathrm{Rx}=$ disease relevant prescription and $1 \mathrm{P}=1$ physician billing code within \pm 6 months of the date of the disease relevant prescription)' was selected to identify PKM patients aged $\geq 20$ with sensitivity of $77.8 \%$, specificity of $99.9 \%$, PPV of $76.9 \%$, and NPV of $99.9 \%$ because it outperformed the other drug algorithms with an estimated prevalence of $0.32 \%$.

The two optimal algorithms in those aged $\geq 65$ are highlighted in table 3 . The nondrug algorithm was the same for those aged $\geq 20$ but ' 1 prescription and 1 physician billing code within \pm 6 months' performed the best (sensitivity $=75.9 \%, \mathrm{PPV}=87.3 \%)$ as it involved a shorter time period compared to ' 1 prescription and 1 physi- 


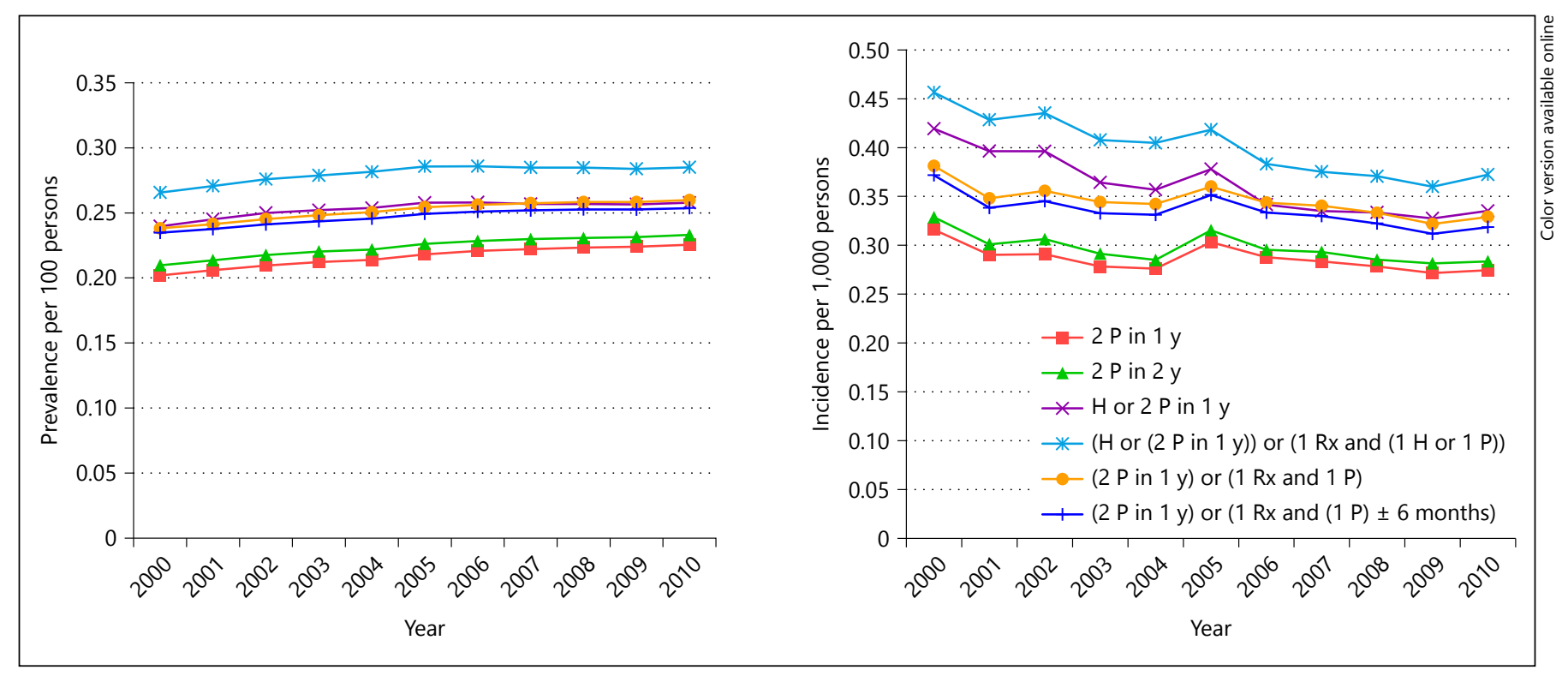

Fig. 2. $\mathrm{P}=$ Physician billing code; $\mathrm{y}=$ years; $\mathrm{H}=$ hospitalization diagnosis code; $\mathrm{Rx}=$ prescription including levodopa drugs, $\mathrm{MAO}-\mathrm{B}$ inhibitors, dopamine agonists and COMT inhibitors.

cian billing code in 1 year' and fewer databases compared to and ' 1 prescription and ( 1 hospitalization diagnosis code or 1 physician billing code) within \pm 6 months'. The prevalence estimates for the optimal nondrug and drug algorithms in those aged $\geq 65$ were $1.2 \%$ compared to $1.3 \%$ in the reference standard.

We reviewed the false negative and false positive cases for PKM in those aged $\geq 20$ for ' 2 physician billing codes in 1 year' to identify the reasons for misclassification. There were 68 false negatives for PKM (present in the EMR records but not in administrative data), where 33 had documentation of a physician diagnosis for PD and 14 had other PKM not specified, 8 had Lewy Body disease, 7 had drug-induced PKM, 3 had Huntington's disease, 1 had vascular PKM, 1 had multiple system atrophy and 1 was on anti-PD medication. We found 42 false positives (present in the administrative data but not in the EMR), where 7 had 'possible' PKM, 6 had 'no mention' of PKM in the EMR chart, 4 had PKM in administrative data, which preceded the start of the EMR record, 4 had poorly documented EMRs, 1 was ruled out in the EMR and 20 were clearly miscoded in the administrative data as: 12 with essential tremor, 3 with mental health disorders, 2 with Huntington's disease, 1 with Parkinsonism-like symptoms, 1 with orofacial dystonia and 1 with a gait disorder.

We found the age-standardized population prevalence and incidence rates of PKM in Ontario in 2010 using our optimal nondrug algorithm of ' 2 physician billing codes in 1 year' to be 0.23 per 100 persons and 0.27 per 1,000 persons, respectively in those aged $\geq 20$ (fig. 2 ; online suppl. table 1), and 1.09 per 100 persons and 1.52 per 1,000 persons, respectively in those aged $\geq 65$. (fig. 3 ; online suppl. table 2). We also observed a gradual increase in the population prevalence of PKM in those aged $\geq 20$ from 2000 until 2006 and then the trend appeared relatively stable after 2006 using the more accurate algorithms (fig. 2; online suppl. table 1a). There was a gradual decrease in incidence of PKM in those aged $\geq 20$ during the same time period, which appeared to stabilize after 2006 (fig. 2; online suppl. table $1 \mathrm{~b}$ ). In those aged $\geq 65$, we observed a somewhat similar pattern in prevalence over time compared to younger adults with PKM; however, there was a gradual decline in incidence over time (fig. 3; online suppl. table 2).

\section{Discussion}

We found that patients with PKM can be accurately identified from administrative databases using a primary care EMR as a reference standard. The optimal algorithm, ' 2 physician billing codes in 1 year', could be used in both adult and senior populations. Using the drug algorithm, ' 1 prescription and 1 physician billing code within \pm 6 months' to identify PKM in patients aged $\geq 65$ also pro- 


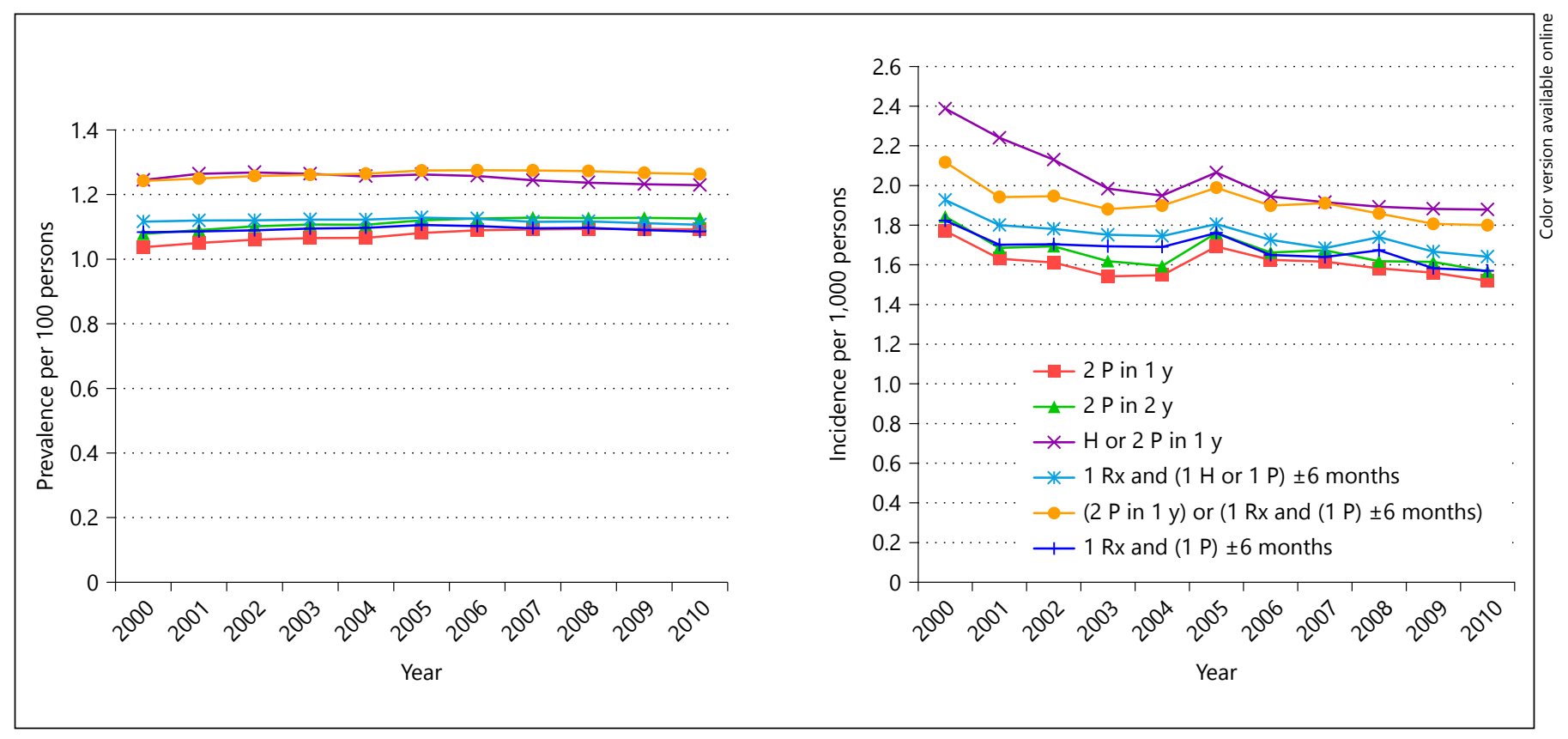

Fig. 3. $\mathrm{P}=$ Physician billing code; $\mathrm{y}=$ years; $\mathrm{H}=$ hospitalization diagnosis code; $\mathrm{Rx}=$ prescription including levodopa drugs, $\mathrm{MAO}-\mathrm{B}$ inhibitors, dopamine agonists and COMT inhibitors.

duced good validity indices and provides an alternative algorithm when prescription databases are available.

In comparing our study findings to the literature, our validity estimates are generally higher and we used a reference standard more reflective of the general population. Szumski and Cheng used targeted sampling from a Veterans administrative (VA) healthcare database (98\% male) where all possible PKM patients were identified using the ICD-9 code 332.0 and EMR chart review of 'definite' or 'possibly' PD cases were all considered a likely working diagnosis of PD [8]. Previous studies with administrative databases have demonstrated that using the ICD-9 diagnostic code 332.0 does not allow distinction of idiopathic PD and secondary PKM $[8,11,12,16-18]$ and is suboptimal when used alone leading to an underestimation of disease prevalence [11]. Despite these differences with our study, increasing the frequency of physician billing codes increased the PPV but decreased the sensitivity, which was consistent with our study findings. A tiered consensus algorithm based on a count $\geq 332.0$ codes and use of specialty clinic (e.g., movement disorder clinic) over a 3-year period was identified as their best algorithm with a sensitivity $87.4 \%$, specificity $45.4 \%$, PPV $83.2 \%$ and NPV $53.8 \%$ [8]. This study's validated algorithms consistently demonstrated low specificities and NPVs likely due to their sampling method and working diagnosis of PD [8].

Validating Data Algorithms for Parkinsonism
Another validation study involving a Pacific Northwest VA database with EMR chart review identified a random sample of PKM cases and non-cases based on ICD-9 codes (332, 332.1, 333 and 781.0), PD prescriptions and controls from a medical clinic [11]. Using ICD-9 codes to identify PKM was not accurate (sensitivity $18.7 \%$, specificity $99.9 \%$, and PPV $81.0 \%$ ) but adding PD drugs increased the sensitivity to $37.9 \%$ and decreased the PPV to $60.4 \%$ [11]. Although low validity indices, the combination of ICD-9 codes and prescriptions did outperform using one database alone, consistent with our findings in those aged $\geq 65$ years.

Also, another study using Medicare administrative claims with reference standards of patient self-report and PD medications identified potential PKM patients using ICD-9 codes $(332.0,332.1,333.0,333.1)$ [10]. The best algorithm involved the presence of all ICD-9 codes in any claims with a sensitivity of $61 \%$, specificity of $99 \%$ and PPV of 65\% [10]. Using patient-reported diagnoses from surveys as a reference standard has been demonstrated to have poor sensitivity because patients may not be aware of their diagnoses and works better for medical conditions that are well-defined and easier to diagnose [19]. Therefore, in comparison to our study findings, the majority of studies sampled patients using ICD-9 diagnostic codes for $\mathrm{PD} / \mathrm{PKM}$ in administrative data and as a result 
unbiased estimates of accuracy could not be generated because prevalence estimates for PD/PKM were not measured in the validation study sample. Also, the validated algorithms in previous studies produced low validity indices, used mainly veteran populations and varied reference standards not entirely reflective of the general population.

The disease prevalence for PKM was similar in both the validation sample and from our optimal administrative data algorithms. The prevalence in the reference standard was $0.32 \%$ in those aged $\geq 20$ consistent with $0.28 \%$ using ' 2 physician billing codes in 1 year' and identical using the optimal drug algorithm, '(2 physician billing codes in 1 year) or ( 1 prescription and 1 physician billing code within \pm 6 months)'. The prevalence estimates for PD/PKM reported in other Canadian studies are $0.069-0.36 \%[1,12,20-22]$, which is similar to our study findings. The prevalence for PKM in those $\geq 65$ living in Ontario are $1.46 \%$ [1] and $1.23 \%$ [23] for men and $1.12 \%$ [1] and $0.74 \%$ [23] for women, which is also similar to our study findings. Similarly, the age-standardized annual incidence rates reported in our study were consistent with previously published international studies (including a systematic review) in North America (127207 per 100,000 person years; $96-121$ per 100,000 person years) and Europe (5-346 per 100,000 person years) [17, $18,24]$.

This study has certain strengths as we performed a vigorous and robust, good quality validation study, which followed guidelines $[7,13]$. Specifically, we derived our patients with PKM and non-cases from a random sample of primary care patients $(\mathrm{N}=73,003)$ reflective of the general population. We also determined the prevalence of PKM in the reference standard, which was consistent with our optimal administrative data algorithms. There are limitations to this study. While we identified an optimal administrative drug algorithm in adults aged $\geq 20$, we recognized a prescription database is limited to those aged $\geq 65$. Although differences in population mix may impact the generalizability of our results, this study was done on a population that is similar to the Ontario population in terms of sex, age and presence of comorbid conditions [25]; therefore, we believe our findings to be reasonably generalizable, if not only in Ontario but to the rest of Canada and has the potential to inform other countries with similar administrative databases.

In conclusion, patients with PKM can be identified with a good degree of accuracy using administrative data algorithms. These algorithms will facilitate the establish- ment of patient cohorts with PKM. Future research in this area should apply such algorithms to other data sources in different provinces across Canada to more accurately define the current epidemiology and natural history of $\mathrm{PD} / \mathrm{PKM}$.

\section{Acknowledgment}

We wish to acknowledge the membership of Neurological Health Charities Canada and the Public Health Agency of Canada for their contribution to the success of this initiative. The opinions expressed in this publication are those of the authors/researchers, and do not necessarily reflect the official views of the Public Health Agency of Canada and are independent from the funding sources. No endorsement by ICES or the Ontario MOHLTC is intended or should be inferred.

This study is part of the National Population Health Study of Neurological Conditions. Funding for the study was provided by the Public Health Agency of Canada. This study was also supported by the Institute of Clinical Evaluative Sciences (ICES), which is funded by an annual grant from the Ontario Ministry of Health and Long-Term Care (MOHLTC). Drs. Debra Butt, Karen $\mathrm{Tu}$, and Liisa Jaakkimainen are supported by a Department of Family and Community Medicine (DFCM) Investigator Award by the Research Department of the University of Toronto. Dr. Karen Tu is also supported by a Canadian Institutes of Health Research (CIHR) Fellowship Award in Primary Care. Dr. Noah Ivers is supported by a CIHR Fellowship Award in Clinical Research and by a DFCM Fellowship Award from the University of Toronto.

All authors contributed to the preparation of the manuscript and have met the authorship criteria. Dr. Butt had full access to all the data in the study and takes responsibility for the integrity of the data and the accuracy of the data analysis. The author contributions are as follows: all authors contributed to study concept and design. Debra Butt, Karen Tu, Jacqueline Young, Diane Green, Myra Wang, and Mark Guttman contributed to data analysis and all authors contributed to the interpretation of data. Dr. Butt drafted the manuscript and all authors provided critical revision of the manuscript for important intellectual content. All authors approved the final version of the manuscript.

\section{Disclosure Statement}

Debra Butt, Karen Tu, Jacqueline Young, Diane Green, Myra Wang, Noah Ivers and Liisa Jaakkimainen have no financial or other relationships that might lead to a conflict of interest for this study. Robert Lam has received an educational grant from Pfizer. Mark Guttman has received funds for educational activities and advisory boards from Teva Neuroscience, Novartis Pharma, Medtronics Canada, Merck-Serono, Bristol Meyers Squibb, Isis Pharmaceuticals Inc. and UCB Canada. Mark Guttman is a consultant for CHDI Foundation and NPF. Mark Guttman has also received research grant support over the last two years from $\mathrm{NIH}$, CHDI, NPF, Merck, Teva, and Neurosearch.
Butt/Tu/Young/Green/Wang/Ivers/ Jaakkimainen/Lam/Guttman 


\section{References}

1 Guttman M, Slaughter PM, Theriault ME, 10 Noyes K, Liu H, Holloway R, Dick AW: AcDeBoer DP, Naylor CD: Burden of Parkinsonism: a population-based study. Mov Disord 2003;18:313-319.

$>2$ Damiano AM, Snyder C, Strausser B, Willian $\mathrm{MK}$ : A review of health-related quality-of-life concepts and measures for Parkinson's disease. Qual Life Res 1999;8:235-243.

3 Guttman M, Kish SJ, Furukawa Y: Current concepts in the diagnosis and management of Parkinson's disease. CMAJ 2003;168:293-301.

$\checkmark 4$ Wirdefeldt K, Adami HO, Cole P, Trichopoulos D, Mandel J: Epidemiology and etiology of Parkinson's disease: a review of the evidence. Eur J Epidemiol 2011;26(suppl 1):S1-S58.

$>5$ Dorsey ER, Constantinescu R, Thompson JP, Biglan KM, Holloway RG, Kieburtz K, Marshall FJ, Ravina BM, Schifitto G, Siderowf A, Tanner CM: Projected number of people with Parkinson disease in the most populous nations, 2005 through 2030. Neurology 2007;68: 384-386.

6 Lix LM, Yogendran MS, Leslie WD, Shaw SY, Baumgartner R, Bowman C, Metge C, Gumel A, Hux J, James RC: Using multiple data features improved the validity of osteoporosis case ascertainment from administrative databases. J Clin Epidemiol 2008;61:1250-1260.

$>7$ Benchimol EI, Manuel DG, To T, Griffiths AM, Rabeneck L, Guttmann A: Development and use of reporting guidelines for assessing the quality of validation studies of health administrative data. J Clin Epidemiol 2011;64: 821-829.

$>8$ Szumski NR, Cheng EM: Optimizing algorithms to identify Parkinson's disease cases within an administrative database. Mov Disord 2009;24:51-56.

$>9$ White D, Moore S, Waring S, Cook K, Lai E: Identifying incident cases of Parkinsonism among veterans using a tertiary medical center. Mov Disord 2007;22:915-923. curacy of Medicare claims data in identifying Parkinsonism cases: comparison with the Medicare current beneficiary survey. Mov Disord 2007;22:509-514.

11 Swarztrauber K, Anau J, Peters D: Identifying and distinguishing cases of Parkinsonism and Parkinson's disease using ICD-9 CM codes and pharmacy data. Mov Disord 2005;20: 964-970.

12 Harris MA, Koehoorn M, Teschke K: Ongoing challenges to finding people with Parkinson's disease for epidemiological studies: a comparison of population-level case ascertainment methods. Parkinsonism Relat Disord 2011;17:464-469.

13 Widdifield J, Labrecque J, Lix L, Paterson JM, Bernatsky S, Tu K, Ivers N, Bombardier C: Systematic review and critical appraisal of validation studies to identify rheumatic diseases in health administrative databases. Arthritis Care Res (Hoboken) 2013;65:1490-1503

14 Williams J, Young W: A summary of studies on the quality of healthcare administrative databases in Canada; in Goel V, Williams JI, Young W, Anderson GM, Blackstein-Hirsch P, Fooks C, Naylor CD, (eds): Patterns of Health Care in Ontario: The ICES Practice Atlas, ed 2. Ottawa: Canadian Medical Association, 1996, pp 339-346.

15 Tu K, Campbell NR, Duong-Hua M, McAlister FA: Hypertension management in the elderly has improved: Ontario prescribing trends, 1994 to 2002. Hypertension 2005;45: 1113-1118.

16 Cheng EM, Swarztrauber K, Siderowf AD, Eisa MS, Lee M, Vassar S, Jacob E, Vickrey BG: Association of specialist involvement and quality of care for Parkinson's disease. Mov Disord 2007;22:515-522.
17 Allyson Jones C, Wayne Martin WR, Wieler M, King-Jesso P, Voaklander DC: Incidence and mortality of Parkinson's disease in older Canadians. Parkinsonism Relat Disord 2012; 18:327-331.

18 Van Den Eeden SK, Tanner CM, Bernstein AL, Fross RD, Leimpeter A, Bloch DA, Nelson LM: Incidence of Parkinson's disease: variation by age, gender, and race/ethnicity. Am J Epidemiol 2003;157:1015-1022.

19 Kehoe R, Wu SY, Leske MC, Chylack LT Jr: Comparing self-reported and physician-reported medical history. Am J Epidemiol 1994; 139:813-818.

20 Lai BC, Schulzer M, Marion S, Teschke K, Tsui JK: The prevalence of Parkinson's disease in British Columbia, Canada, estimated by using drug tracer methodology. Parkinsonism Relat Disord 2003;9:233-238.

21 Svenson LW, Platt GH, Woodhead SE: Geographic variations in the prevalence rates of Parkinson's disease in Alberta. Can J Neurol Sci 1993;20:307-311.

22 Snow B, Wiens M, Hertzman C, Calne D: A community survey of Parkinson's disease. CMAJ 1989;141:418-422.

23 Finkelstein MM, Jerrett M: A study of the relationships between Parkinson's disease and markers of traffic-derived and environmental manganese air pollution in two Canadian cities. Environ Res 2007;104:420-432.

24 Von Campenhausen S, Bornschein B, Wick R, Botzel K, Sampaio C, Poewe W, Oertel W, Siebert U, Berger K, Dodel R: Prevalence and incidence of Parkinson's disease in Europe. Eur Neuropsychopharmacol 2005;15:473490

25 Jaakkimainen RL, Schultz S, Tu K: Effects of implementing electronic medical records on primary care billings and payments: a beforeafter study. CMAJ Open 2013, DOI: 10.9778/ cmajo.20120039. 